JURNAL ILMIAH KEBIDANAN IMELDA

Vol.7, No.2, September 2021, pp.81-84

ISSN: 2597-7180 (Online), 2442-8116 (Print)

http://jurnal.uimedan.ac.id/index.php/JURNALKEBIDANAN

\title{
TINGKAT PENGETAHUAN REMAJA PUTRI KELAS III SMP TENTANG MENARCHE
}

Eva Nirwana Natalia Hutabarat

Universitas Imelda Medan, Indonesia

\begin{tabular}{l}
\hline \hline Article Info \\
\hline Article history: \\
Received Aug 28, 2021 \\
Revised Sep 14, 2021 \\
Accepted Sep 28, 2021 \\
\hline
\end{tabular}

Keywords:

Knowledge

Young women

Menarche

\begin{abstract}
Menarche is the first menstruation, the first menstrual cycle or the first menstrual bleeding in women. From a social and medical point of view, the condition is seen as an important event of female puberty, as a sign of fertility. Adolescents who know about menarche will feel happy when they experience it. While negative feelings such as anxiety, fear, shame and confusion. This study aims to determine the level of knowledge of young women about menarche at SMP St.Yoseph Medan. This research method is descriptive research. The number of samples as many as 53 people, sampling using total sampling technique. From 53 respondents, the results showed that the level of knowledge of respondents about menarche was mostly in the sufficient category, which was $50.9 \%$. While the good category is $37.7 \%$, and the less category is $11.3 \%$. Based on the age of respondents with sufficient knowledge as much as 39.6\% aged 14-15 years and the minority with less knowledge $1.9 \%$ aged $12-13$ years. Based on the sources of information, quite a lot of respondents obtained information from the mass media $15.1 \%$ and the minority $1.9 \%$. From the results of this study, it is hoped that the school and parents of students can play an active role in providing reproductive health, especially menarche.
\end{abstract}

This is an open access article under the CC BY-SAlicense.

Corresponding Author:

Eva Nirwana Natalia Hutabarat

Program Studi S1 Kebidanan,

Universitas Imelda Medan,

Jl. Bilal No. 52 Kelurahan Pulo Brayan Darat I Kecamatan Medan Timur, Medan - Sumatera Utara.

Email: nirwana.eva88@gmail.com

\section{INTRODUCTION}

Masa remaja berlangsung antara umur 13-18 tahun. Pada masa remaja manusia tidak dapat disebut sudah dewasa tetapi tidak dapat pula disebut anak-anak. Menurut Word Health Organitation (WHO), remaja adalah periode usia antara 10-19 tahun, sedangkan Perserikatan Bangsa-Bangsa (PBB) menyebut remaja adalah kaum muda (Youth) untuk usia antara 15-24 tahun (Kusmiran, 2011). Peristiwa terpenting yang terjadi pada gadis remaja adalah datangnya haid pertama kali, biasanya sekitar umur 10-16 tahun yang dinamakan menarche (Jones, 2005).

Menarche adalah menstruasi atau haid pertama kali yang dialami oleh perempuan yang merupakan cirri kedewasaan seorang perempuan yang sehat dan tidak hamil. Menarche terjadi akibat peningkatan LH dan FSH yang merangsang sel target ovarium. LH dan FSH berkombinasi dengan reseptornya untuk meningkatkan laju kecepatan sekresi, pertumbuhan dan poliferasi sel. Rangsangan ini dihasilkan dari pengaktifan sistem second messenger adenosine-monophosphate cyclic dalam sitoplasmasel ovarium untuk 
menstimulasi ovarium agar memproduksi estrogen dan progesteron. Estrogen dan progesterone akan menstimulasi uterus dan kelenjar payudara agar siap untuk terjadinya ovulasi. Ovulasi yang tidak dibuahi akan menjadi menstruasi.

Di Amerika sekitar 95\% remaja putri mempunyai tanda pubertas pada umur 12 tahun dan umur rata-rata 12,5 tahun. Menarche atau haid pertama merupakan salah satu perubahan pubertas yang pasti dialami setiap remaja putri. Di Inggris usia rata-rata untuk mencapai menarche adalah pada usia 18,8 tahun (Jamaluddin, 2004). Di Indonesia remaja putri pada waktu menarche bervariasi antara 10-19 tahun dan rata-rata menarche 12,5 tahun (Wiknjosastro, 2003).

Pada survey awal terdapat 15 responden yang diberi pertanyaan tentang menarche dan hasil yang diperoleh hanya 4 responden yang memiliki pengetahuan baik (7,6\%). Sisanya 6 responden tergolong berpengetahuan cukup (11,3\%), dan yang berpengetahuan kurang sejumlah 5 responden $(9,4 \%)$. Berdasarkan uraian diatas maka peneliti tertarik untuk meneliti "Bagaimana Tingkat Pengetahuan Remaja Putri Kelas III SMP Tentang Menarche di SMP St. Yoseph Medan Periode Mei - Julitahun 2021”.

\section{RESEARCH METHOD}

Jenis penelitian yang bersifat deskriptif untuk mengetahui pengetahuan Remaja Putri Kelas III SMP Tentang Menarche di SMP St. Yoseph Medan Periode Mei-Juli tahun 2021. Penelitian ini menggunakan data primer yang dapat melalui wawancara responden dengan menggunakan kuesioner.

\section{RESULTS AND ANALYSIS}

\subsection{Hasil}

Pengumpulan data dilakukan pada bulan Mei - Juli di SMP St. Yoseph Medan tahun 2021, dengan cara membagikan kuesioner yang berisi 20 pertanyaan berbentuk multiple choice. Pengisian kuesioner dilakukan sendiri oleh masing-masing responden dengan didampingi peneliti. Setiap data yang terkumpul dari masing-masing peneliti. Setiap data yang terkumpul diperiksa kelengkapan pengisian apabila belum lengkap maka responden diminta untuk melengkapinya. Dari hasil penelitian ditemukan data responden yaitu sebagai berikut:

1. Distribusi Pengetahuan Responden

Tabel 1. Distribusi Tingkat Pengetahuan Remaja Tentang Menarche Di SMP St. Yoseph Medan

\begin{tabular}{clcc}
\hline No & Pengetahuan & Frekuensi & Persentase \\
\hline 1 & Baik & 20 & 37,7 \\
\hline 2 & Cukup & 27 & 50,9 \\
\hline 3 & Kurang & 6 & 11,3 \\
\hline & Jumlah & $\mathbf{5 3}$ & $\mathbf{1 0 0}$ \\
\hline
\end{tabular}

Sumber: Data Primer (Hasil PendataanTahun 2021)

Dari tabel diatas dapat dilihat mayoritas remaja putri berpengetahuan cukup yaitu 27 orang (50,9\%) dan minoritas berpengetahuan kurang yaitu 6 orang $(11,3 \%)$.

\section{Distribusi Pengetahuan Responden Berdasarkan Umur}

Tabel 2. Distribusi Tingkat Pengetahuan Responden Tentang Menarche SMP berdasarkan Umur Di SMP St. Yoseph Medan

\begin{tabular}{|c|c|c|c|c|c|c|c|c|c|}
\hline \multirow[t]{3}{*}{ No } & \multirow[t]{3}{*}{ Umur } & \multicolumn{6}{|c|}{ Pengetahuan } & \multirow{2}{*}{\multicolumn{2}{|c|}{ Total }} \\
\hline & & \multicolumn{2}{|c|}{ Baik } & \multicolumn{2}{|c|}{ Cukup } & \multicolumn{2}{|c|}{ Kurang } & & \\
\hline & & $\mathbf{F}$ & $\%$ & $\mathbf{F}$ & $\%$ & $\mathbf{F}$ & $\%$ & $\mathbf{F}$ & $\%$ \\
\hline 1 & 12-13 Tahun & 7 & 13,2 & 4 & 7,6 & 5 & 9,4 & 16 & 30.2 \\
\hline 2 & 14-15 Tahun & 13 & 24,7 & 23 & 43,4 & 1 & 1,9 & 37 & 69,8 \\
\hline & Total & 20 & 37,7 & 27 & 51 & 6 & 11,3 & 53 & 100 \\
\hline
\end{tabular}

Sumber: Data Primer (Hasil Pendataan Tahun 2021)

Dari tabel diatas diketahui bahwa mayoritas responden berpengetahuan cukup sebanyak 23 orang (43.4\%) umur 14-15 tahun dan minoritas berpengetahuan kurang sebanyak 1 orang (1,9\%) umur 14-15 tahun. 
3. Distribusi Pengetahuan Responden Berdasarkan Sumber Informasi

Tabel 3. Distribusi Tingkat Pengetahuan Responden Tentang Menarche Di SMP St. Yoseph Medan

\begin{tabular}{|c|c|c|c|c|c|c|c|c|c|}
\hline \multirow[t]{3}{*}{ No } & \multirow[t]{3}{*}{ SumberInformasi } & \multicolumn{6}{|c|}{ Pengetahuan } & \multicolumn{2}{|c|}{ Total } \\
\hline & & \multicolumn{2}{|c|}{ Baik } & \multicolumn{2}{|c|}{ Cukup } & \multicolumn{2}{|c|}{ Kurang } & & \\
\hline & & $\mathbf{F}$ & $\%$ & $\mathbf{F}$ & $\%$ & $\mathbf{F}$ & $\%$ & $\mathbf{F}$ & $\%$ \\
\hline 1 & Media massa & 4 & 7,5 & 8 & 15,1 & 1 & 1.9 & 13 & 24,5 \\
\hline 2 & TenagaKesehatan & 7 & 13,2 & 7 & 13,2 & 1 & 1.9 & 15 & 28,3 \\
\hline 3 & Teman & 5 & 9,4 & 9 & 17 & 3 & 5,7 & 17 & 32,1 \\
\hline 4 & Orang Tua & 4 & 7,5 & 3 & 5,7 & 6 & 11,4 & 8 & 15,1 \\
\hline & Total & 20 & 37,6 & 27 & 51 & 6 & 11,4 & 53 & 100 \\
\hline
\end{tabular}

Sumber: Data Primer (Hasil PendataanTahun 2021)

Dari tabel diatas menunjukan bahwa mayoritas responden memperoleh informasi dari teman sebanyak 9 orang $(17 \%)$ berpengetahuan cukup dan minoritas memperoleh informasi dari media massa, tenaga kesehatan, dan orang tua masing-masing 1 orang $(1,9 \%)$ berpengetahuan kurang.

\subsection{Pembahasan}

Dari penelitian yang berjudul "Tingkat Pengetahuan Remaja Putri Kelas III SMP Tentang Menarche Periode Mei - Juli tahun 2021” adalah sebagai berikut:

\section{Distribusi Responden Berdasarkan Pengetahuan}

Tingkat pengetahuan responden tentang menarche mayoritas yang berpengetahuan cukup yaitu 27 orang (50,9\%), dan minoritas berpengetahuan kurang yaitu 6 orang (11,3\%). Menurut Fitriani (2011), pengetahuan merupakan hasil dari tahu, dan ini terjadi setelah orang melakukan penginderaan terhadap suatu objek tertentu. Sebagian besar pengetahuan manusia diperoleh melalui pendidikan, pengalaman sendiri maupun pengalaman yang diperoleh dari orang lain dan lingkungan sekitarnya, sehingga pengetahuan sangat penting untuk terbentuknya perilaku seseorang. Maka cukupnya angka pengetahuan yang diperoleh remaja putri dalam penelitian karena kurangnya informasi yang diperoleh, serta dipengaruhi oleh beberapa faktor, misalnya: umur dan sumber informasi. Hal ini dilihat dari hasil penelitian bahwa semakin bertambah umur, dan sumber informasi menunjukan bahwa tingkat pengetahuan responden semakin baik.

\section{Distribusi Responden Berdasarkan Umur}

Dari hasil penelitian diketahui bahwa mayoritas berpengetahuan cukup sebanyak 23 orang (43,4\%) umur 14-15 tahun dan minoritas berpengetahuan kurang banyak 1 orang (1,9\%) umur 14-15 tahun. Menurut Mubarak (2021), dengan bertambahnya umur seseorang memperoleh pengalaman perubahan aspek fisik dan psikologis (mental). Menurut asumsi peneliti masih ditemui responden yang berpengetahuan kurang pada usia 14-15 tahun, hal ini disebabkan masih kurangnya pemahaman responden tentang menarche, karena responden pada umur 14-15 tahun masih kurang dalam hal pengalaman tentang menarche.

\section{Distribusi Responden Berdasarkan Sumber Informasi}

Dari hasil penelitian yang dilakukan bahwa mayoritas responden remaja putri memperoleh informasi mayoritas bersumber dari teman sebanyak 9 orang $(17 \%)$ dan minoritas bersumber dari media massa, tenaga kesehatan, dan orang tua masing-masing 1 orang (1,9\%). Menurut Notoatmodjo (2002), sumber informasi menyangkut asal dari mendata/ informasi maupun pengetahuan tersebut diperoleh atau segala sesuatu yang menjadi perantara dalam manyampaikan informasi merangsang fikiran dan kemampuan. Maka menurut asumsi peneliti bahwa informasi yang diperoleh dari berbagai sumber dapat mempengaruhi tingkat pendidikan responden yang mana sumber informasi ini dapat dimiliki dan dipegang sebagai acuan untuk meningkatkan kualitas seseorang dalam penerapan profesinya, misalnya sumberi informasi yang diperoleh dari media massa, teman dan sebagainya.

\section{CONCLUSION}

Dari hasil penelitian yang berjudul "Tingkat Pengetahuan Remaja Putri Kelas III SMP Tentang Menarche di SMP St. Yoseph Medan Periode Mei-Juli Tahun 2021" yang dilakukan dapat disimpulkan sebagai berikut:

1. Dari 53 orang responden mayoritas berpengetahuan cukup yaitu sebanyak 27 orang $(50,9 \%)$ dan minoritas berpengetahuan kurang sebanyak 6 orang $(11,3 \%)$.

2. Dari 53 orang responden mayoritas berpengetahuan cukup sebanyak 23 orang (43.4\%) umur 14-15 tahun dan minoritas berpengetahuan kurang sebanyak 1 orang (1.9\%). 
3. Dari 53 orang responden mayoritas memperoleh informasi dari teman sebanyak 9 orang (17\%) yang berpengetahuan cukup dan minoritas memperoleh informasi dari media massa, tenaga kesehatan dan orang tua masing-masing 1 orang $(1.9 \%)$ yang berpengetahuan kurang.

\section{REFERENCES}

Arikunto, Suharsimi, 2005. Prosedur penelitian. Jakarta: Rineka Cipta.

Fitri. S., 2011. Promosi Kesehatan. Jakarta: Graha Ilmu.

Hanifah. M. J., 2007. Haid dan Siklusnya. Dalam: Wiknjosastro, H., Saifuddin, A.,B., Rachibandhi. T., eds. Ilmu Kandungan Ed 2. Jakarta: Yayasan Bina Pustaka Sarono Prawirohardjo

Jamaluddin,2004.http://library.Helvetia.ac.id//gdl.php? mod=browse \&op=read\&id=supthelpp=idarosidah6. [Diakes pada 10 maret 2021]

Jones.D.L., 2005. Setiap Wanita. Indonesia. Jakarta: Dela Pratasa Publising.

Kusmiran. E., 2011. Kesehatan Reprodeksi Remaja dan Wanita. Jakarta: Salemba Medika.

Machfoedz. I.M.S., 2009. Metodologi Penelitian, Yogyakarta. Fitramaya

Mubarak. I. W., 2011. Promosi Kesehatan Untuk Kebidanan. Jakarta: Salemba Medika.

Notoatmodjo. N., 2002. Masa Remaja. Jakarta: Depdikbud.

Pinem.S., 2010. Kesehatan Reproduksi dan Kontrasepsi. Jakarta: TIM.

Rismalinda, Tumbuh Kembang Anak dan Remaja. Jakarta: Sagung Seto.

Sibagariang. E.E., 2010. Kesehatan Reproduksi Wanita. Jakarta: TIM.

Wiknjosastro, 2003. Ilmu Kandungan Ed 2. Jakarta: Yayasan Bina Pustaka.

Winaris, 2010. 100 Tanya Jawab Kesehatan Untuk Remaja. Jogjakarta: Tunas Publising.

\section{BIOGRAPHIES OF AUTHORS}

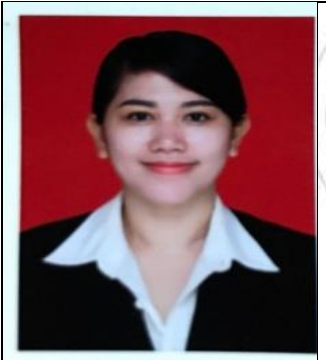

Eva Nirwana Hutabarat, SKM, M.KM, Gelar D-III diperoleh dari Akademi Kebidanan Imelda Medan, Jurusan Kebidanan pada tahun 2010. Gelar Sarjana diperoleh dari STIKes Deli Husada Deli Tua, Jurusan Ilmu Kesehatan Masyarakat Tahun 2013. Magister Kesehatan diperoleh dari Universitas Sumatera Utara, Jurusan Ilmu Kesehatan Masyarakat pada tahun 2018. Saat ini aktif sebagai dosen tetap di Prodi D-III Kebidanan Universitas Imelda Medan. 